\title{
Hypergravity Stimulation Enhances PC12 Neuron-Like Cell Differentiation
}

\author{
Giada Graziana Genchi, ${ }^{1}$ Francesca Cialdai, ${ }^{2}$ Monica Monici, ${ }^{2}$ Barbara Mazzolai, \\ Virgilio Mattoli, ${ }^{1}$ and Gianni Ciofani ${ }^{1}$ \\ ${ }^{1}$ Istituto Italiano di Tecnologia, Center for Micro-BioRobotics @SSSA, Viale Rinaldo Piaggio 34, 56025 Pontedera (Pisa), Italy \\ ${ }^{2}$ ASAcampus Joint Laboratory, ASA Research Division, Department of Experimental and Clinical Biomedical Sciences, \\ University of Florence, Viale Pieraccini 6, 50139 Florence, Italy
}

Correspondence should be addressed to Giada Graziana Genchi; giada.genchi@iit.it and Gianni Ciofani; gianni.ciofani@iit.it

Received 4 November 2014; Revised 8 January 2015; Accepted 27 January 2015

Academic Editor: Aijun Wang

Copyright (c) 2015 Giada Graziana Genchi et al. This is an open access article distributed under the Creative Commons Attribution License, which permits unrestricted use, distribution, and reproduction in any medium, provided the original work is properly cited.

\begin{abstract}
Altered gravity is a strong physical cue able to elicit different cellular responses, representing a largely uninvestigated opportunity for tissue engineering/regenerative medicine applications. Our recent studies have shown that both proliferation and differentiation of $\mathrm{C} 2 \mathrm{C} 12$ skeletal muscle cells can be enhanced by hypergravity treatment; given these results, PC12 neuron-like cells were chosen to test the hypothesis that hypergravity stimulation might also affect the behavior of neuronal cells, in particular promoting an enhanced differentiated phenotype. PC12 cells were thus cultured under differentiating conditions for either $12 \mathrm{~h}$ or $72 \mathrm{~h}$ before being stimulated with different values of hypergravity $(50 \mathrm{~g}$ and $150 \mathrm{~g})$. Effects of hypergravity were evaluated at transcriptional level $1 \mathrm{~h}$ and $48 \mathrm{~h}$ after the stimulation, and at protein level $48 \mathrm{~h}$ from hypergravity exposure, to assess its influence on neurite development over increasing differentiation times. PC12 differentiation resulted strongly affected by the hypergravity treatments; in particular, neurite length was significantly enhanced after exposure to high acceleration values. The achieved results suggest that hypergravity might induce a faster and higher neuronal differentiation and encourage further investigations on the potential of hypergravity in the preparation of cellular constructs for regenerative medicine and tissue engineering purposes.
\end{abstract}

\section{Introduction}

Altered gravity represents a powerful physical cue able to exert deeply modeling effects on both anatomy and function of living organisms [1-10]. It is indeed well known that exposure to microgravity implies detrimental effects on skeletal muscle mass [11], composition [12], and contractility [3], and on bone density, with long-term effects even after return to normal gravity [13]. Microgravity instead has contrasting effects on the nervous system, in some cases not perturbing cell differentiation and assembling [14-16], in other cases strongly altering cell morphology and functions [17-19] or even improving stem cell differentiation into neurons [2022].

For its demonstrated effects from the cellular level up to the whole organism level, microgravity has been proposed in regenerative medicine for a wide range of applications, including self-assembling of healthy and diseased tissues, and drug testing. [23-26]. For instance, simulated microgravity was applied to bone marrow stromal cells for transplantation in contusion model mice, significantly improving motor function [27]. PC12 adrenal medullary cells were tested under microgravity conditions as well, and neuroendocrine organoids were thus successfully achieved [28].

Many other examples focused on simulated microgravity for both basic science investigations and regenerative medicine purposes can be found in the literature, whereas few reports deal with hypergravity effects on biological systems. Among these, it is worth to mention a study on the vestibular system of Oryzias latipes, demonstrating an early upregulation of the $c$-fos gene transcription as soon as $30 \mathrm{~min}$ after a $3 \mathrm{~g}$ exposure [5]. Another study showed that a $2.9 \mathrm{~g}$ 
hypergravity treatment proved to inhibit bone resorption in ovariectomized rats [7]. Other experiments on cellular systems were performed on human umbilical vein endothelial cells (3.5 g for $96 \mathrm{~h} \mathrm{[29])} \mathrm{and} \mathrm{on} \mathrm{SH-SY5Y} \mathrm{neuroblastoma}$ cells ( $2 \mathrm{~g}$ over $6 \mathrm{~min}$ [30]), respectively, showing an altered cytoskeletal distribution and an enhanced lamellar protrusive activity. Concerning hypergravity effects on skeletal muscle, C2C12 myoblast proliferation and differentiation were shown to be significantly increased by 5,10 , and $20 \mathrm{~g}$ treatments [31]. In the field of tissue engineering, it has been shown that hypergravity helps to promote a higher expression of cardiomyocyte proteins in mesenchymal stem cells and that the latter can be successfully grafted in a mouse model of cardiac infarction supporting an improved functional recovery [32].

As evident in most of the reported examples, low hypergravity values (1-10g) have been usually studied for their implications on human health, being those typically acting on astronauts in the early stages of the journey from the Earth to space. A wider range of hypergravity values has instead poorly been investigated, leaving largely undisclosed hypergravity potentialities for both basic and translational science. The exploration of strong hypergravity values indeed opens opportunities to a better understanding of cellular responses to extreme conditions, and to the preparation of constructs with desired phenotype for cell transplantation and drug screening procedures.

In the light of the previously mentioned studies, and aiming at developing new strategies in the field of neuronal tissue engineering, it was hypothesized that hypergravity might also affect PC12 neuron-like cell behavior, in particular during differentiation. For these reasons, high acceleration values ( $50 \mathrm{~g}$ and $150 \mathrm{~g}$ ) were chosen for hypergravity stimulation and applied for $1 \mathrm{~h}$ at different time intervals since the differentiation induction. Several qualitative and quantitative analyses (fluorescent staining, metabolism assay, gene expression analysis) were performed, highlighting as the hypergravity stimulation caused a slight increment of metabolic activity, but also a more marked enhancement of neuronal differentiation. These results demonstrate as hypergravity efficiently works as a straightforward physical stimulation for biomedical applications, and it can have important implications in the field of peripheral nerve regeneration.

\section{Materials and Methods}

2.1. Cell Culture. PC12 cells (derived from a rat pheochromocytoma) represent a model for neuronal differentiation, as they can reversibly respond to the administration of the nerve growth factor (NGF) and express a sympathetic neuronal phenotype [33]. PC12 cells were seeded at a density of 20,000 cells $/ \mathrm{cm}^{2}$ on tissue culture polystyrene (PS) disks, previously coated with a $100 \mu \mathrm{g} / \mathrm{mL}$ collagen I (Sigma) solution to promote cell adhesion. PC12 were cultured in Dulbecco's modified Eagle medium (DMEM), supplemented with 10\% horse serum (HS), 5\% fetal bovine serum (FBS), $100 \mathrm{IU} / \mathrm{mL}$ penicillin, $100 \mu \mathrm{g} / \mathrm{mL}$ streptomycin, and $2 \mathrm{mM}$ L-glutamine. Differentiation was induced by administration of a lowserum (1\% FBS) medium, supplemented with $50 \mathrm{ng} / \mathrm{mL}$ NGF (Sigma). PC12 cells were maintained at $37^{\circ} \mathrm{C}$ in a $5 \% \mathrm{CO}_{2}$, saturated humidity atmosphere. Adhesion and proliferation were allowed for $48 \mathrm{~h}$ before performing experiments.

Differentiation was induced for two different time intervals ( $12 \mathrm{~h}$ and $72 \mathrm{~h}$ ) before applying stimulation, in order to evaluate the effect of hypergravity on phenotype at different development stages. A predifferentiation period of $12 \mathrm{~h}$ was chosen to assess the effect of hypergravity on the early events of neuritogenesis, whereas a predifferentiation period of $72 \mathrm{~h}$ was chosen to study any perturbations on later stages of neuritogenesis [34]. Experimental protocols are schematized in Figure 1(a).

For hypergravity stimulation, PS disks seeded with PC12 cells were placed over cured polydimethylsiloxane (10:1 base to cross-linking agent ratio, curing temperature: $60^{\circ} \mathrm{C}$ ), filling $90 \%$ of the volume of $50 \mathrm{~mL}$ centrifuge tubes. The remaining $10 \%$ of the volume of the tubes was filled with cell culture medium, in order to exclude shear stress effects during stimulation (Figure 1(b)). Hypergravity (50 g and $150 \mathrm{~g}$ ) was applied with a bench centrifuge (312R Hettich Zentrifugen, equipped with a 1617 rotor) thermostated at $25^{\circ} \mathrm{C}$ for $1 \mathrm{~h}$. Control cultures were kept at $1 \mathrm{~g}$ and $25^{\circ} \mathrm{C}$ for $1 \mathrm{~h}$. At the end of hypergravity stimulation, cultures were transferred to 24-well plates and kept under either proliferating or differentiating conditions before being analyzed.

Analyses were mostly performed $48 \mathrm{~h}$ after hypergravity treatment, as a trade-off between the timeframe usually needed to observe effects of treatments on PC12 cell phenotype under differentiating conditions [35] and the potential occurrence of recovery effects after hypergravity stimulation [36]. However, analyses on gene transcription were performed also $1 \mathrm{~h}$ after hypergravity treatment as alterations at gene transcriptional levels can occur even at extremely early time points after treatments.

2.2. PC12 Cell Proliferation. Analyses were performed $48 \mathrm{~h}$ after hypergravity stimulation. Cell proliferation was assessed with the WST-1 cell metabolism assay (based on the 2-(4iodophenyl)-3-(4-nitophenyl)-5-(2,4-disulfophenyl)-2H-tetrazolium monosodium salt, provided in a pre-mix electrocoupling solution, BioVision). Cell cultures were treated with $400 \mu \mathrm{L}$ of culture medium added with $40 \mu \mathrm{L}$ of pre-mix solution for $2 \mathrm{~h}$ and, finally, absorbance was read at $450 \mathrm{~nm}$ with a microplate reader (Victor X3, Perkin Elmer).

\subsection{Fluorescence Staining of Proliferating and Differentiating} Cultures. Fluorescence staining was performed on cultures $48 \mathrm{~h}$ after hypergravity stimulation. Samples were first rinsed with 1X PBS (PBS) and fixed with a $4 \%$ paraformaldehyde (Sigma) solution in PBS for $20 \mathrm{~min}$ at $4^{\circ} \mathrm{C}$. After three rinses with PBS (5 min each), samples were incubated with $1 \mathrm{mg} / \mathrm{mL}$ sodium borohydride (Sigma) in PBS for $10 \mathrm{~min}$ to reduce or suppress aspecific fluorescence. Cellular membranes were then permeabilized with $0.1 \%$ Triton X-100 (Sigma-Aldrich) in PBS for $15 \mathrm{~min}$. Aspecific binding sites were saturated with $10 \%$ goat serum (GS, Gibco) in PBS for $1 \mathrm{~h}$. Cell morphology of proliferating cultures was investigated by staining cytoskeletal actin and nuclei with a $60 \mathrm{ng} / \mu \mathrm{L}$ TRITCphalloidin (Millipore) solution and a $1 \mu \mathrm{M}$ DAPI solution in 

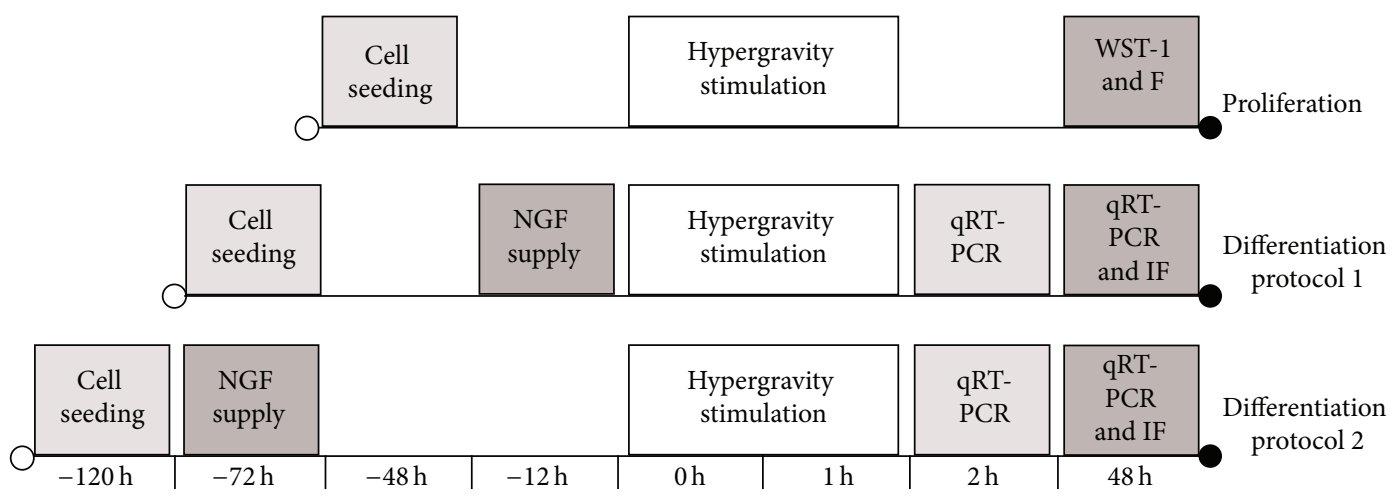

(a)

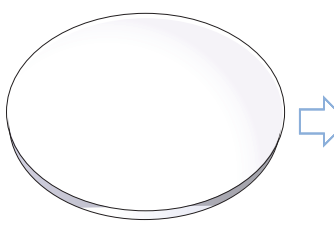

Tissue culture polystyrene disk

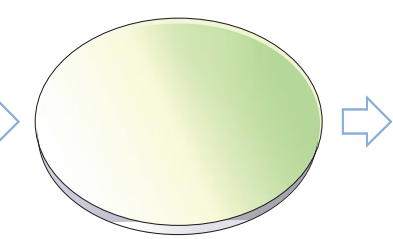

Collagen

coating

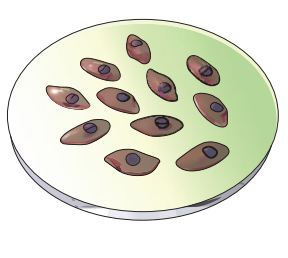

PC12 cell seeding

(b)

FIGURE 1: Experimental timeline. "F" stands for "fluorescent staining" and "IF" stands for "immunofluorescent staining" (a). Schematization of the setup used to expose PC12 cells to hypergravity (b).

$10 \%$ GS, respectively. After three rinses in PBS (5 min each), samples were imaged with a confocal laser scanning microscope (C2 s, Nikon). For imaging of neurites in differentiating cultures, a rabbit polyclonal antitubulin IgG (Sigma, diluted 1:75 in 10\% GS), or a rabbit monoclonal antineurofilament IgG (Millipore, diluted 1:200 in 10\% GS) were used as primary antibodies after saturation on different sets of samples (stimulated with the same hypergravity conditions). Cultures were incubated with primary antibodies at $37^{\circ} \mathrm{C}$ for $45 \mathrm{~min}$ and then washed four times with $10 \%$ GS ( 5 min each rinse). A fluorescent goat anti-rabbit IgG (Invitrogen, diluted 1:250 in $10 \%$ GS) was then used as a secondary antibody, with an incubation at room temperature for $30 \mathrm{~min}$, while nuclei were counterstained with a $1 \mu \mathrm{M}$ DAPI solution in $10 \%$ GS. Unbound and weakly bound antibodies were removed with $0.45 \mathrm{M} \mathrm{NaCl}$ PBS (1 min rinse). Samples were finally washed twice with PBS (5 min each rinse) and images were acquired with the confocal microscope.

Neurite lengths were measured with ImageJ software. For statistical purposes, at least 30 neurites per culture were considered. Neurofilament-positive neurites and nuclei were identified with ImageJ software as well, considering more than 500 cells per sample type.

2.4. Gene Transcription Analysis: qRT-PCR. Investigations on gene transcription were performed $1 \mathrm{~h}$ and $48 \mathrm{~h}$ after hypergravity treatment. Total RNA was isolated from cell cultures by using High Pure RNA Isolation kit (Roche) according to the manufacturer's protocol. RNA concentration was measured at $260 \mathrm{~nm}$ with a spectrophotometer (NanoDrop 2000, Thermo Scientific). Retrotranscription of $300 \mathrm{ng}$ of RNA into cDNA was performed by using the iScriptTM Reverse Transcription Supermix (Bio-Rad). The thermal protocol included an incubation at $25^{\circ} \mathrm{C}$ for $5 \mathrm{~min}$, followed by an incubation at $42^{\circ} \mathrm{C}$ for $45 \mathrm{~min}$ and a final incubation at $85^{\circ} \mathrm{C}$ for $5 \mathrm{~min}$ to stop the reaction. Then, cDNA was diluted 10 times with ultrapure water to undergo amplification.

Neurofilament-66 (Ina) and $\beta 3$-tubulin (Tubb3) gene transcription was analyzed through quantitative RT-PCR with a CFX Connect Real-Time PCR Detection System (BioRad). Glyceraldehyde 3-phosphate dehydrogenase (Gapdh) was considered as reference gene. For PCR procedures, cDNA $(5 \mu \mathrm{L})$ was mixed to specific forward and reverse primers (at a final concentration of $8 \mu \mathrm{M}$ ) and to SsoAdvanced SYBR Green Supermix (Bio-Rad). The following thermal protocol was applied: one period of $30 \mathrm{~s}$ at $98^{\circ} \mathrm{C}$ for polymerase activation, followed by 40 cycles at $98^{\circ} \mathrm{C}$ for $3 \mathrm{~s}$ and $60^{\circ} \mathrm{C}$ for $15 \mathrm{~s}$. After the last reaction cycle, melting curves were obtained through a temperature ramp from $65^{\circ} \mathrm{C}$ to $95^{\circ} \mathrm{C}$, with $0.5^{\circ} \mathrm{C} / \mathrm{s}$ increments, to exclude unspecific products. Each PCR run included "no template" sample and all tests were performed in triplicate. The cycle threshold $(\mathrm{Ct})$ value relative of control sample was considered for the calculation of $\Delta \Delta \mathrm{Ct}$ (difference between $\Delta \mathrm{Ct}$ values calculated from the difference between $\mathrm{Ct}$ of target and of reference gene) for the samples. Primer sequences (forward and reverse) of the investigated genes are reported in Table 1. 


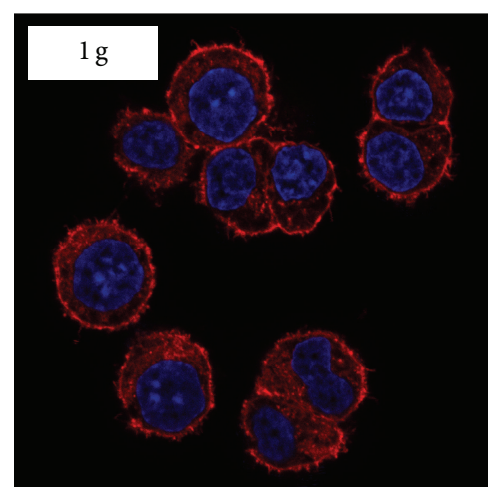

$20 \mu \mathrm{m}$

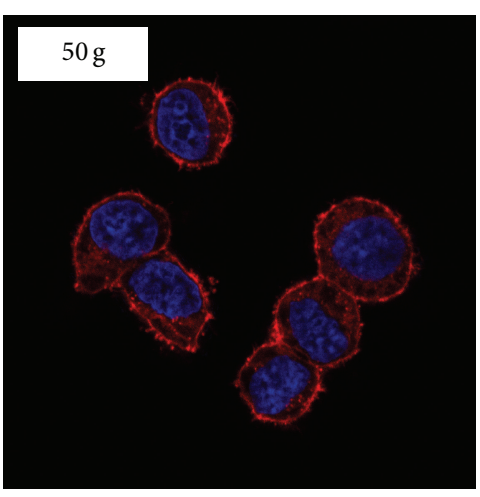

$20 \mu \mathrm{m}$

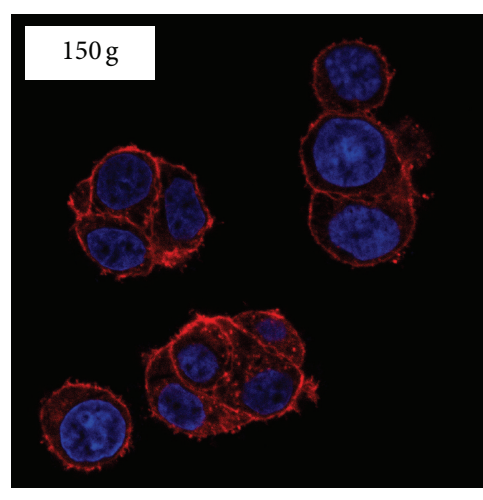

$20 \mu \mathrm{m}$

(a)

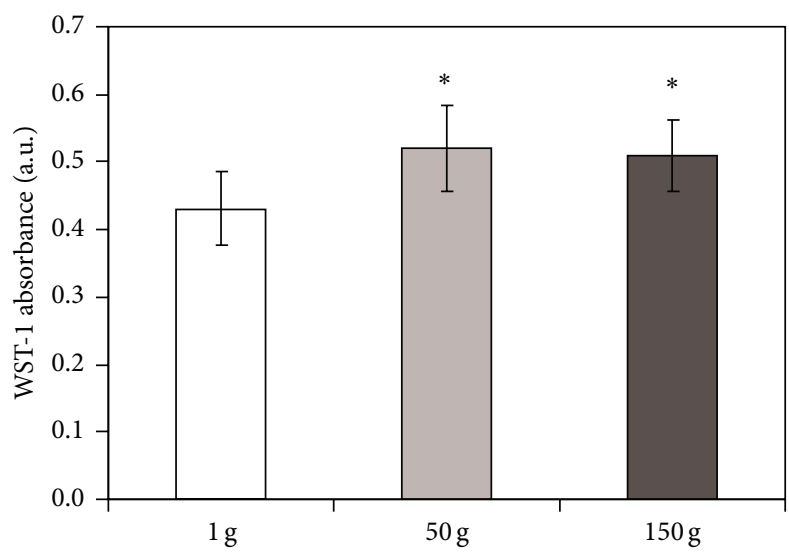

(b)

Figure 2: Confocal images of cytoskeletal actin (in red) and nuclei (in blue) in proliferating PC12 cells $48 \mathrm{~h}$ after hypergravity treatment (a); quantification of cell viability through WST-1 assay after hypergravity treatment (b). ${ }^{*} P<0.05$.

TABLE 1: Primer sequences for qRT-PCR analysis.

\begin{tabular}{ll}
\hline Gene & Sequences \\
\hline $\begin{array}{l}\text { Glyceraldehyde } \\
\text { 3-phosphate }\end{array}$ & F: $5^{\prime}$-AACCTGCCAAGTATGATGAC-3' \\
$\begin{array}{l}\text { dehydrogenase } \\
(\text { Gapdh })\end{array}$ & R: $5^{\prime}$-GGAGTTGCTGTTGAAGTCA-3' \\
\hline $\begin{array}{l}\text { Neurofilament-66 } \\
(\text { Ina })\end{array}$ & F: $5^{\prime}$-AGGCTGGAAGGTAAACTCAGAC-3' \\
\hline $\begin{array}{l}\text { R3-tubulin } \\
\text { (Tubb) }\end{array}$ & F: $5^{\prime}$-ATTCATTCCAGGTGGACGTGAAGCAGGA-3' \\
\hline
\end{tabular}

2.5. Statistical Analysis. Each experiment was repeated three times and a number of three samples were considered for each experimental session. Data were presented as mean \pm standard deviation. Analysis of variance (ANOVA) was performed, followed by Bonferroni's post hoc test. Neurite length distributions were shown on box-plots and expressed as median $\pm 95 \%$ confidence interval; Kruskal-Wallis analysis followed by Dunn's post hoc test was performed to test for significance. A $P$ value $<0.05$ was considered significant.

\section{Results}

Under proliferating conditions, cell morphology after hypergravity stimulation was found qualitatively comparable to that observed in control cultures; as shown in Figure 2(a), cells retained their typical round morphology with very small protrusions and were homogeneously attached to the substrate after both $50 \mathrm{~g}$ and $150 \mathrm{~g}$ treatment.

Instead, cell metabolism was found slightly but significantly higher (of about 20\%) after hypergravity application with respect to the control cultures (Figure 2(b)).

Concerning transcriptional levels of differentiation marker genes in cells differentiated for $12 \mathrm{~h}$ prior to hypergravity stimulation, a significant upregulation of Ina (1.9 fold at $150 \mathrm{~g}$ ) and downregulation of Tubb3 gene (1.7-fold at $50 \mathrm{~g}$ and 1.8 -fold at $150 \mathrm{~g}$ ) transcription were found immediately (1h) after the treatment (Figure 3(a)). The transcription of Tubb3 appeared upregulated after $48 \mathrm{~h}$ for the higher acceleration tested, being 1.4 -fold in comparison to the control (Figure 3(b)).

In cells differentiated for $72 \mathrm{~h}$ prior to hypergravity stimulation, an upregulation of Ina (1.3 fold at $50 \mathrm{~g}$ ) was found immediately after the treatment (Figure 3(c)). This upregulation became even higher (2-fold at $50 \mathrm{~g}$ ) after $48 \mathrm{~h}$ 


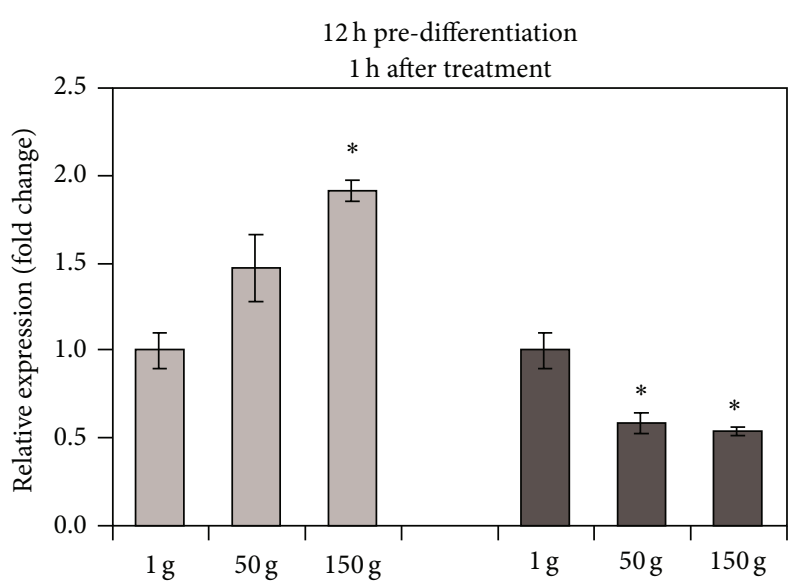

(a)

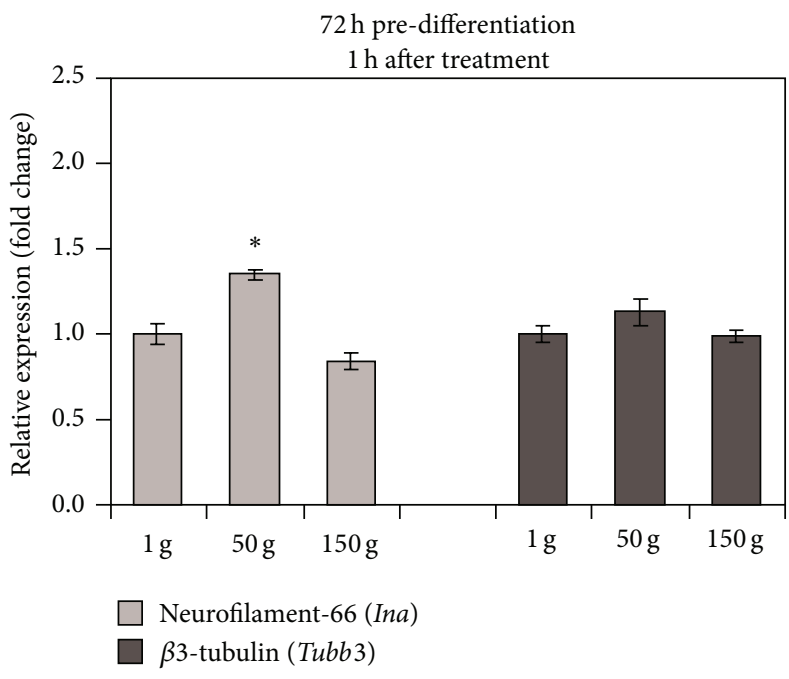

(c)

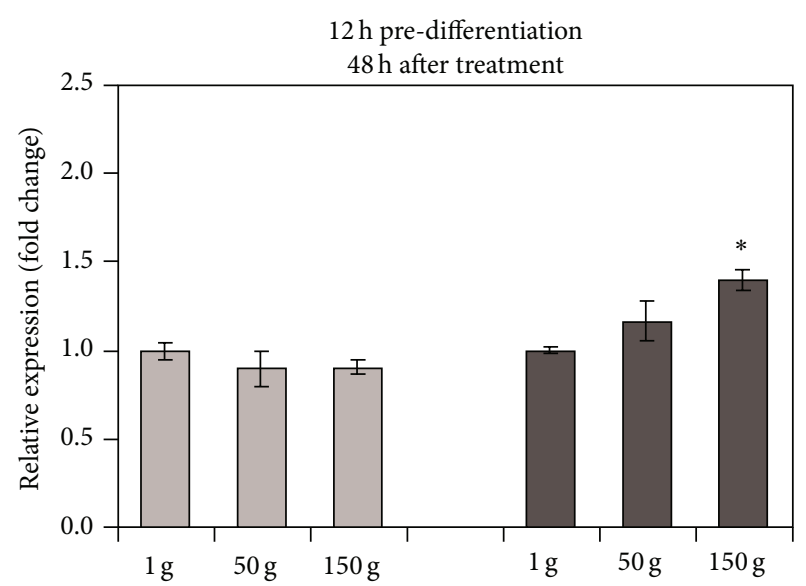

(b)

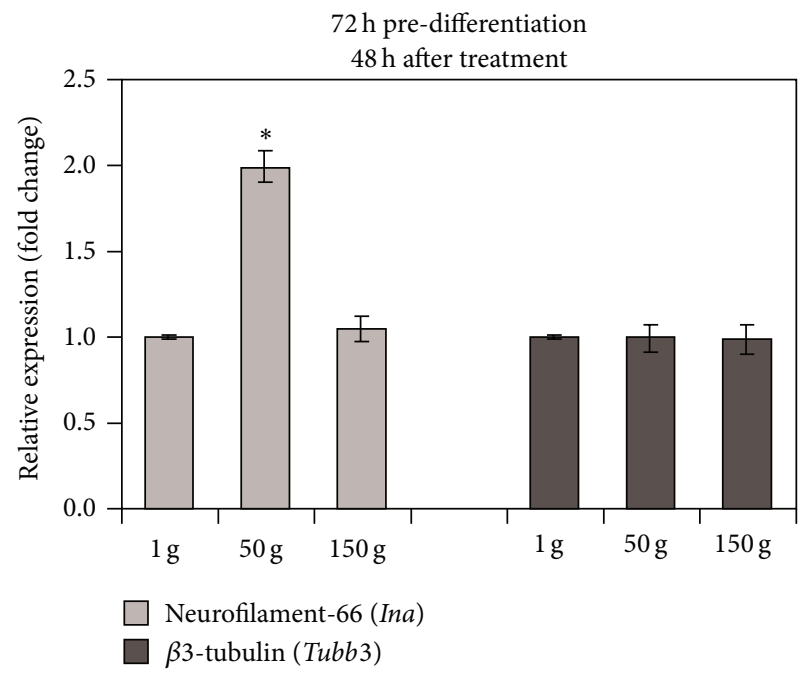

(d)

FIGURE 3: qRT-PCR results for neurofilament-66 (Ina) and $\beta 3$-tubulin (Tubb3) gene transcription $1 \mathrm{~h}$ (a, c) and $48 \mathrm{~h}$ (b, d) after hypergravity treatment on PC12 cells predifferentiated for $12 \mathrm{~h}(\mathrm{a}, \mathrm{b})$ and $72 \mathrm{~h}(\mathrm{c}, \mathrm{d}){ }^{*} \mathrm{P}<0.01$.

(Figure 3(d)). All of the transcriptional levels of Tubb3, instead, remained constant in cells predifferentiated for $72 \mathrm{~h}$.

Immunofluorescent staining of $\beta 3$-tubulin was performed on cultures predifferentiated for either $12 \mathrm{~h}$ (Figure 4(a)) or $72 \mathrm{~h}$ (Figure 4(b)) with NGF, $48 \mathrm{~h}$ after hypergravity stimulation. The most significant effects of hypergravity were represented by evidently longer $\beta 3$-tubulin positive neurites in cells exposed to $150 \mathrm{~g}$ stimulation with respect to those at lower acceleration values. As shown in Figure 4(b), this evidence was more pronounced in the cultures predifferentiated for $72 \mathrm{~h}$, where PC12 cells seemed to have a higher length and number of neurites after $150 \mathrm{~g}$ stimulation.

After $\beta 3$-tubulin staining, the neurite lengths were measured by using low magnification fluorescence images (representative fields are provided as Supplemental Data, see Figure S1 in the Supplementary Material available online at http://dx.doi.org/10.1155/2015/748121), and their distribution was analyzed. As shown in Figure 5 with the box plot of the neurite lengths, the $150 \mathrm{~g}$ hypergravity treatment was effective at determining the emission of significantly longer neurites in PC12 cells predifferentiated for $12 \mathrm{~h}$ with respect to the lower acceleration values. Specifically, median neurite lengths were about $55 \mu \mathrm{m}$ (for $1 \mathrm{~g}$ ); $40 \mu \mathrm{m}$ (for $50 \mathrm{~g}$ ); and $70 \mu \mathrm{m}$ (for $150 \mathrm{~g}$; $P<0.05)$ in cells predifferentiated for $12 \mathrm{~h}$.

Even in cells predifferentiated for $72 \mathrm{~h}$, the $150 \mathrm{~g}$ treatment promoted the sprouting of longer neurites with respect to the lower acceleration values. Median neurite lengths were about $70 \mu \mathrm{m}$ (for $1 \mathrm{~g}$ ); $80 \mu \mathrm{m}$ (for $50 \mathrm{~g}$ ), and $100 \mu \mathrm{m}$ (for $150 \mathrm{~g}$; $P<0.05)$. Neurite length distributions are also reported as frequency histograms in Supplemental Data (Figure S2).

In control cells predifferentiated for $12 \mathrm{~h}$, neurofilament66 protein (as evidenced by immunofluorescent staining) surrounded nuclei as a neat ring-like structure, and a few neurites resulted positive to staining. In the cultures that underwent $50 \mathrm{~g}$ and $150 \mathrm{~g}$ stimulation (Figure 6(a)), neurofilament- 66 showed a neat polarization on one side of the cell nucleus and a peculiar arrangement in the neurites, where the 


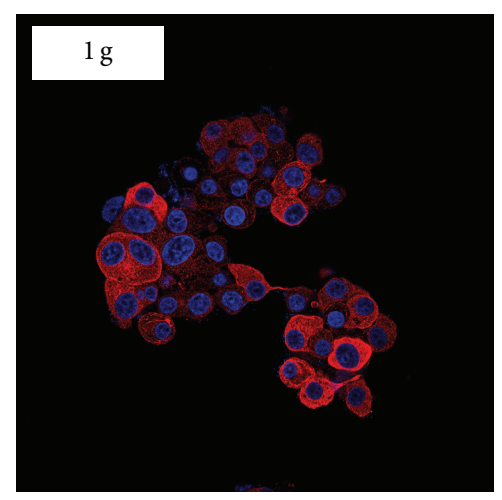

$50 \mu \mathrm{m}$

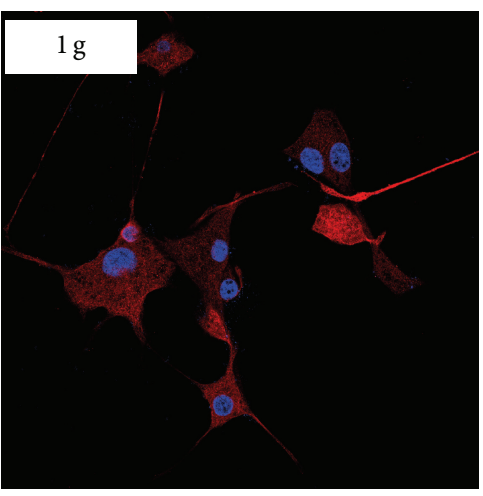

$50 \mu \mathrm{m}$

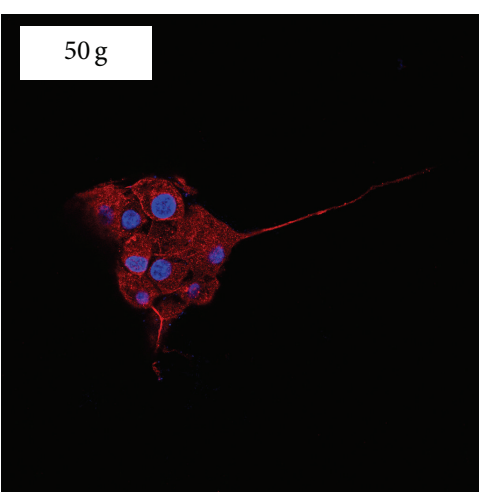

$50 \mu \mathrm{m}$

(a)

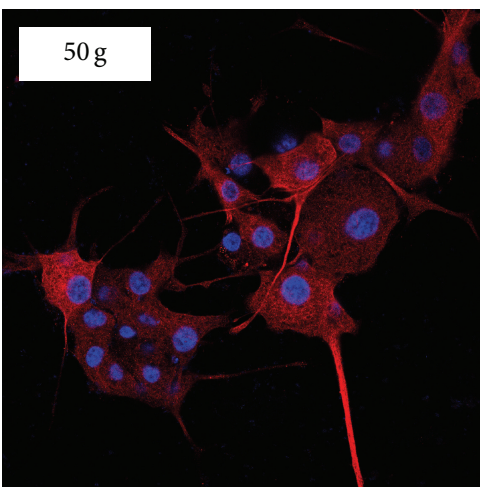

$50 \mu \mathrm{m}$
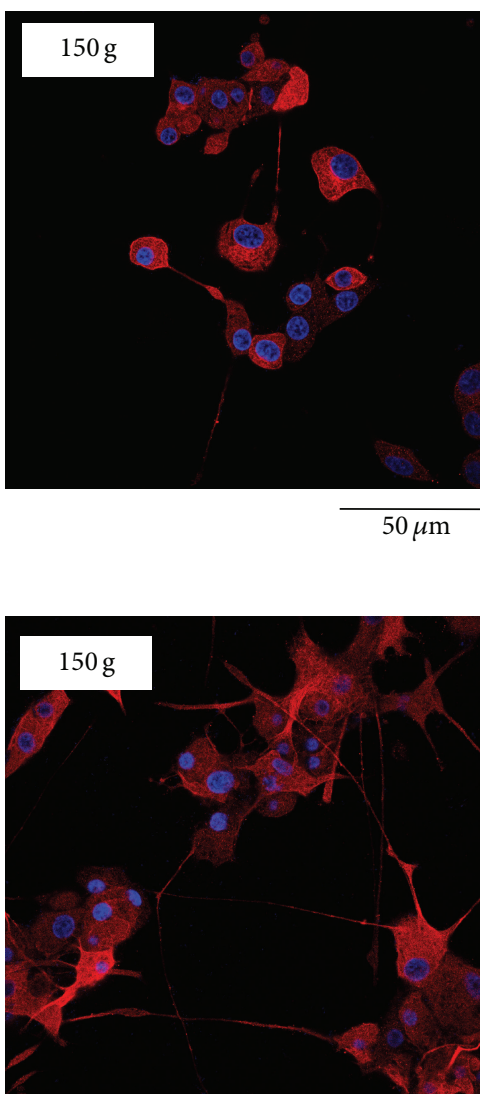

$50 \mu \mathrm{m}$

(b)

FIGURE 4: Confocal images of $\beta 3$-tubulin (in red) and nuclei (in blue) in PC12 cell cultures predifferentiated for $12 \mathrm{~h}$ (a) and $72 \mathrm{~h}$ (b) $48 \mathrm{~h}$ after hypergravity treatment.

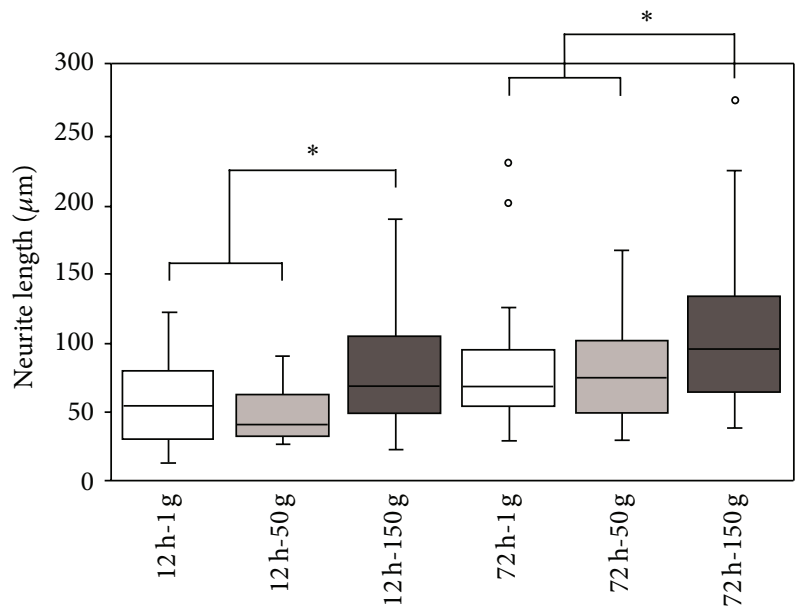

Figure 5: Box plot of the neurite lengths measured $48 \mathrm{~h}$ after hypergravity treatment. PC12 cells were differentiated for $12 \mathrm{~h}$ and $72 \mathrm{~h}$ prior to hypergravity treatment. ${ }^{*} \mathrm{P}<0.05$.

staining appeared in the distal portions and in the growth cones. A similar trend was found in cultures that underwent hypergravity stimulation after a $72 \mathrm{~h}$ predifferentiation period. However, in this case, neurofilament-66 polarization was present also in control cells (Figure 6(b)).

Quantitative analysis of neurofilament expression performed on low magnification fluorescence images (representative fields are provided in Supplemental Data, Figure S3) revealed that $\sim 3 \%$ of the cells predifferentiated for $12 \mathrm{~h}$ and exposed to $1 \mathrm{~g}$ had NF-positive neurites. When cells were exposed to $50 \mathrm{~g}$ and $150 \mathrm{~g}$, higher percentages were found ( $\sim 20 \%$ and $\sim 30 \%$ of the cells had NF-positive neurites, resp.; $P<0.05$ in both cases).

In cells predifferentiated for $72 \mathrm{~h}$ and exposed to $1 \mathrm{~g}, \sim$ $10 \%$ of the cells had NF-positive neurites. When cells were exposed to 50 and $150 \mathrm{~g}$, higher percentages were found (15\% and $\sim 40 \%$ of the cells had NF-positive neurites, resp.; $P<$ 0.05 in both cases).

\section{Discussion}

Altered gravity can exert a deep influence on cellular behavior, on tissue functions, and even on whole organisms. Traditionally, microgravity has been investigated mainly because of its dramatic effects on human anatomy and physiology even after a short-term permanence in space [3]. On the other hand, it has been observed that microgravity is an effective 


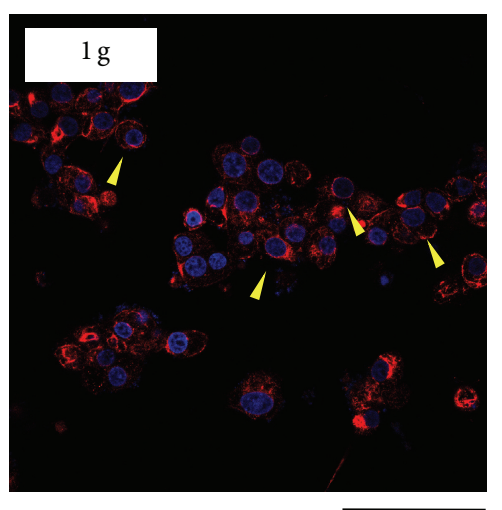

$50 \mu \mathrm{m}$

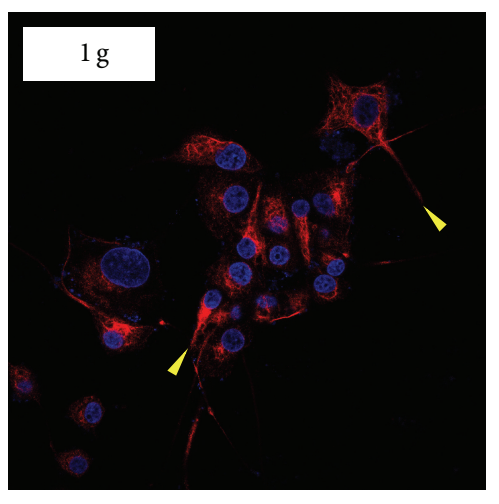

$50 \mu \mathrm{m}$

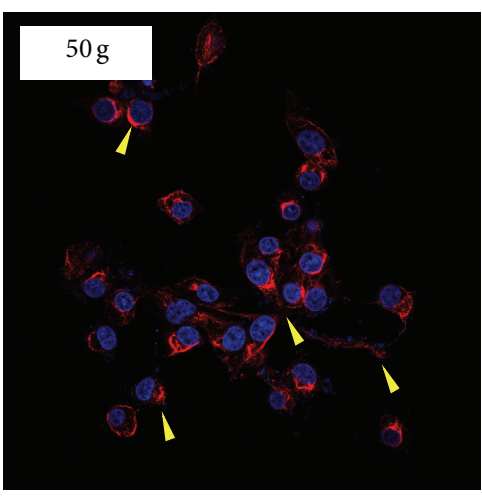

$50 \mu \mathrm{m}$

(a)

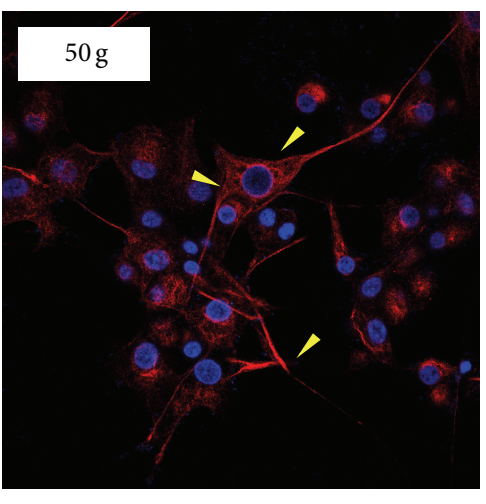

$50 \mu \mathrm{m}$
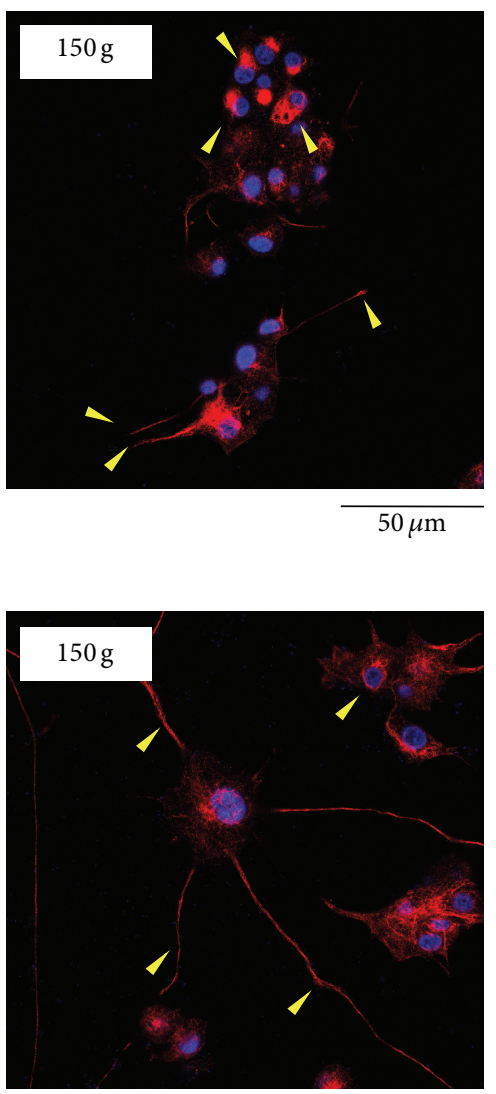

$50 \mu \mathrm{m}$

(b)

FIGURE 6: Confocal images of neurofilament-66 (in red) and nuclei (in blue) in PC12 cell cultures predifferentiated for $12 \mathrm{~h}$ (a) and $72 \mathrm{~h}$ (b) after $48 \mathrm{~h}$ from hypergravity treatment. Arrows evidence neurofilament- 66 organization in a ring-like structure in control cultures, whereas the marker is localized in neurites and in growth cones in hypergravity-stimulated cells.

means to obtain in vitro constructs that could be useful for a wide range of applications $[23,27]$. The application of hypergravity to cell cultures for tissue engineering purposes remains instead relatively unexplored.

To the best of our knowledge, a review of the available literature evidences no significant data about effects on PC12 cells and, more generally, on neuronal cells after exposure to hypergravity. Only one paper reported on SH-SY5Y neuroblastoma cell line behavior after exposure to moderate hypergravity for short periods of time [33].

In the present work, the application of hypergravity conditions to PC12 neuron-like cells resulted in a modest but significant increase of metabolic activity.

In our study, altered gravity conditions were found to affect the transcriptional patterns of genes involved in neuronal maturation depending on the predifferentiation period. The upregulation of neurofilament-66 gene transcription upon hypergravity stimulation could be related to the finding of a different spatial expression pattern of the neurofilament66 protein. The latter was mostly found at distal portions of the neurites rather than in the cell body, which is typical of a more advanced differentiation state $[37,38]$.
Above all, PC12 phenotype development resulted strongly affected by the hypergravity treatments, being neurites significantly longer after stimulation at high acceleration values.

Concerning effects of microgravity on neuronal cells, it has been reported that $1 \mathrm{~h}$ exposure induced damages in rodent neurons, resulting in a diminished neurite network density and neurite size, and in the alteration of $\beta 3$-tubulin localization [36]. Alterations of the NGF and BDNF signaling pathways in cortical neurons were also found under simulated microgravity [39]. When PC12 cells were exposed to a middle-term duration (8 days) microgravity, a reduced neurite extension with respect to $1 \mathrm{~g}$ cultures was demonstrated as well [40]. Other evidences in the literature can be found concerning different cell lines that showed how microgravity affects cytoskeletal proteins and generally implies alterations of their normal structuring. For instance, an investigation on primary osteoblasts suggested how microtubules undergo a frustrated growth or precocious truncation in the presence of microgravity conditions [8]. Another cytoskeletal protein (actin) was found to be widely disorganized, with thickenings at the cell cortex upon exposure to microgravity in human umbilical vein endothelial cells [29]. 
Our findings concerning exposure of $\mathrm{PC} 12$ cells to different hypergravity values showed no qualitative alterations of cytoskeletal f-actin localization with respect to the controls. Our previous study on C2C12 skeletal myoblasts instead showed an increase in cytoplasmic actin filament thickness [31]. By contrast, the literature reports that microtubules (composed of $\alpha$ - and $\beta$-tubulin) are not affected by the exposure to $2 \mathrm{~g}$ hypergravity for $6 \mathrm{~min}$ in SH-SY5Y cells [30].

As previously mentioned, another interesting finding in our study is represented by the different localization of neurofilament-66 within the cells, depending on the stimulation. One of the most pronounced effect of hypergravity on PC12 cells indeed resulted to be neurofilament-66 localization in distal ends of the emitted neurites rather than in the cell bodies (as shown by control cultures). Being neurofilaments involved in the definition of the axonal shape [41, 42], this result seems to suggest that hypergravity may favor neurite development. Taken together, all these findings suggest that a short-term treatment with hypergravity is able to accelerate the differentiation process to an extent typical of longer differentiation times, and thus to promote a faster maturation of PC12 cells toward a neuronal phenotype.

Mechanisms involved in these phenomena are still to be clarified; however, we can hypothesize as hypergravity may act as a mechanical cue able to elicit neuronal development. It is in fact already widely recognized as a mechanical stress, such as stretching in SH-SY5Y cells [43] or shear stress in PC12 cells [44], which can induce an improvement in neurite sprouting. Increased gravity force could thus represent a further physical approach able to trigger signaling pathways (still to be elucidated), and thus to foster cellular responses typical of a mechanical stimulation.

In summary, the obtained results suggest that hypergravity can be considered as a physical cue able to improve neuron-like cell response in terms of differentiation. By driving cell behaviour, hypergravity could represent a simple, safe, and cost-effective approach in the biomedical field that could be used in the in vitro preparation of constructs for tissue engineering and drug screening [45-47] and that could also be considered for futuristic preclinical approaches in the treatment of pathological conditions [48].

\section{Conclusion}

Hypergravity was found to impact on PC12 neuron-like cell differentiation, accelerating neurite emission and increasing neurite length. These findings suggest that a treatment under high gravity conditions could represent a straightforward approach for those applications requiring a well-sustained neurite regeneration for a prompt recovery of function, like, for instance, tissue engineering of the peripheral nervous system. Of course, further studies are necessary to elucidate the role of hypergravity in addressing cell behavior, in particular by investigating its effects on the expression of differentiation markers at a protein level and on the activation of specific signaling pathways. Functional studies as well as the identification of suitable human cell sources are also mandatory for hypergravity treatments to be applied in human healthcare. Current results however provide encouraging evidences on the use of hypergravity as a physical stimulus suitable for the preparation of constructs for regenerative medicine purposes.

\section{Conflict of Interests}

The authors declare no conflict of interests.

\section{Acknowledgments}

Mr. Valfredo Zolesi (Kayser Italia S.r.l., President) is gratefully acknowledged for financial support to the research line. Ms. Antonella Rocca is also acknowledged for technical support.

\section{References}

[1] V. J. Caiozzo, M. J. Baker, R. E. Herrick, M. Tao, and K. M. Baldwin, "Effect of spaceflight on skeletal muscle: mechanical properties and myosin isoform content of a slow muscle," Journal of Applied Physiology, vol. 76, no. 4, pp. 1764-1773, 1994.

[2] G. L. Sanford, S. Harris-Hooker, J. Lui et al., "Influence of changes in gravity on the response of lung and vascular cells to ischemia/reperfusion in vitro," Journal of Gravitational Physiology, vol. 6, no. 1, pp. P27-P28, 1999.

[3] R. H. Fitts, D. R. Riley, and J. J. Widrick, "Functional and structural adaptations of skeletal muscle to microgravity," Journal of Experimental Biology, vol. 204, no. 18, pp. 3201-3208, 2001.

[4] A. Del Signore, S. Mandillo, A. Rizzo et al., "Hippocampal gene expression is modulated by hypergravity," European Journal of Neuroscience, vol. 19, no. 3, pp. 667-677, 2004.

[5] S. Shimomura-Umemura and K. Ijiri, "Effect of hypergravity on expression of the immediate early gene, $\mathrm{c}$-fos, in central nervous system of medaka (Oryzias latipes)," Advances in Space Research, vol. 38 , no. 6, pp. 1082-1088, 2006.

[6] J. Wang, J. Zhang, S. Bai et al., "Simulated microgravity promotes cellular senescence via oxidant stress in rat PC12 cells," Neurochemistry International, vol. 55, no. 7, pp. 710-716, 2009.

[7] T. Ikawa, A. Kawaguchi, T. Okabe et al., "Hypergravity suppresses bone resorption in ovariectomized rats," Advances in Space Research, vol. 47, no. 7, pp. 1214-1224, 2011.

[8] N. Nabavi, A. Khandani, A. Camirand, and R. E. Harrison, "Effects of microgravity on osteoclast bone resorption and osteoblast cytoskeletal organization and adhesion," Bone, vol. 49, no. 5, pp. 965-974, 2011.

[9] J.-H. Xue, L.-H. Chen, H.-Z. Zhao et al., "Differential regulation and recovery of intracellular $\mathrm{Ca}^{2+}$ in cerebral and small mesenteric arterial smooth muscle cells of simulated microgravity rat," PLoS ONE, vol. 6, no. 5, Article ID e19775, 2011.

[10] L. A. Kramer, A. E. Sargsyan, K. M. Hasan, J. D. Polk, and D. R. Hamilton, "Orbital and intracranial effects of microgravity: findings at 3-T MR imaging," Radiology, vol. 263, no. 3, pp. 819827,2012 .

[11] R. H. Fitts, S. W. Trappe, D. L. Costill et al., "Prolonged space flight-induced alterations in the structure and function of human skeletal muscle fibres," The Journal of Physiology, vol. 588, no. 18, pp. 3567-3592, 2010.

[12] D. Sandonà, J.-F. Desaphy, G. M. Camerino et al., "Adaptation of mouse skeletal muscle to long-term microgravity in the MDS mission," PLoS ONE, vol. 7, no. 3, Article ID e33232, 2012. 
[13] R. D. Carpenter, A. D. LeBlanc, H. Evans, J. D. Sibonga, and T. F. Lang, "Long-term changes in the density and structure of the human hip and spine after long-duration spaceflight," Acta Astronautica, vol. 67, no. 1-2, pp. 71-81, 2010.

[14] A. Crestini, C. Zona, P. Sebastiani et al., "Effects of simulated microgravity on the development and maturation of dissociated cortical neuron," In Vitro Cellular \& Developmental BiologyAnimal, vol. 40, no. 5, pp. 159-165, 2004.

[15] D. Husson, L. Gualandris-Parisot, F. Foulquier, S. Grinfield, P. Kan, and A.-M. Duprat, "Differentiation in microgravity of neural and muscle cells of a vertebrate (Amphibian)," Advances in Space Research, vol. 22, no. 2, pp. 303-308, 1998.

[16] D. Demêmes, C. J. Dechesne, S. Venteo, F. Gaven, and J. Raymond, "Development of the rat efferent vestibular system on the ground and in microgravity," Developmental Brain Research, vol. 128, no. 1, pp. 35-44, 2001.

[17] A. Frigeri, D. A. Iacobas, S. Iacobas et al., "Effect of microgravity on gene expression in mouse brain," Experimental Brain Research, vol. 191, no. 3, pp. 289-300, 2008.

[18] F. M. Inglis, K. E. Zuckerman, and R. G. Kalb, "Experiencedependent development of spinal motor neurons," Neuron, vol. 26, no. 2, pp. 299-305, 2000.

[19] A. Ranjan, J. Behari, and B. N. Mallick, "Cytomorphometric changes in hippocampal CA1 neurons exposed to simulated microgravity using rats as model," Frontiers in Neurology, vol. 5, p. 77, 2014.

[20] M. Monticone, Y. Liu, N. Pujic, and R. Cancedda, "Activation of nervous system development genes in bone marrow derived mesenchymal stem cells following spaceflight exposure," Journal of Cellular Biochemistry, vol. 111, no. 2, pp. 442-452, 2010.

[21] J. Chen, R. Liu, Y. Yang et al., "The simulated microgravity enhances the differentiation of mesenchymal stem cells into neurons," Neuroscience Letters, vol. 505, no. 2, pp. 171-175, 2011.

[22] N. Wang, H. Wang, J. Chen et al., "The simulated microgravity enhances multipotential differentiation capacity of bone marrow mesenchymal stem cells," Cytotechnology, vol. 66, no. 1, pp. 119-131, 2014.

[23] D. F. Cameron, J. J. Hushen, L. Colina et al., "Formation and structure of transplantable tissue constructs generated in simulated microgravity from Sertoli cells and neuron precursors," Cell Transplantation, vol. 13, no. 7-8, pp. 755-763, 2004.

[24] M. Takeda, T. Magaki, T. Okazaki et al., "Effects of simulated microgravity on proliferation and chemosensitivity in malignant glioma cells," Neuroscience Letters, vol. 463, no. 1, pp. 5459, 2009.

[25] D. Grimm, M. Wehland, J. Pietsch, G. Aleshcheva, P. Wise, and J. van Loon, "Growing tissues in real and simulated microgravity: new methods for tissue engineering," Tissue Engineering Part B, vol. 20, no. 6, pp. 555-566, 2014.

[26] K. Nakamura, H. Kuga, T. Morisaki et al., "Simulated microgravity culture system for a 3-D carcinoma tissue model," BioTechniques, vol. 33, no. 5, pp. 1068-1076, 2002.

[27] L. Yuge, A. Sasaki, Y. Kawahara et al., "Simulated microgravity maintains the undifferentiated state and enhances the neural repair potential of bone marrow stromal cells," Stem Cells and Development, vol. 20, no. 5, pp. 893-900, 2011.

[28] P. I. Lelkes, D. L. Galvan, G. Thomas Hayman et al., "Simulated microgravity conditions enhance differentiation of cultured PC12 cells towards the neuroendocrine phenotype," In Vitro Cellular and Developmental Biology-Animal, vol. 34, no. 4, pp. 316-325, 1998.
[29] S. Versari, A. Villa, S. Bradamante, and J. A. M. Maier, "Alterations of the actin cytoskeleton and increased nitric oxide synthesis are common features in human primary endothelial cell response to changes in gravity," Biochimica et Biophysica Acta: Molecular Cell Research, vol. 1773, no. 11, pp. 1645-1652, 2007.

[30] H. Rösner, T. Wassermann, W. Möller, and W. Hanke, "Effects of altered gravity on the actin and microtubule cytoskeleton of human SH-SY5Y neuroblastoma cells," Protoplasma, vol. 229, no. 2-4, pp. 225-234, 2006.

[31] G. Ciofani, L. Ricotti, J. Rigosa, A. Menciassi, V. Mattoli, and M. Monici, "Hypergravity effects on myoblast proliferation and differentiation," Journal of Bioscience and Bioengineering, vol. 113, no. 2, pp. 258-261, 2012.

[32] S.-K. Ling, R. Wang, Z.-Q. Dai et al., "Pretreatment of rat bone marrow mesenchymal stem cells with a combination of hypergravity and 5-azacytidine enhances therapeutic efficacy for myocardial infarction," Biotechnology Progress, vol. 27, no. 2, pp. 473-482, 2011.

[33] L. A. Greene and A. S. Tischler, "Establishment of a noradrenergic clonal line of rat adrenal pheochromocytoma cells which respond to nerve growth factor," Proceedings of the National Academy of Sciences of the United States of America, vol. 73, no. 7, pp. 2424-2428, 1976.

[34] K. P. Das, T. M. Freudenrich, and W. R. Mundy, "Assessment of PC12 cell differentiation and neurite growth: a comparison of morphological and neurochemical measures," Neurotoxicology and Teratology, vol. 26, no. 3, pp. 397-406, 2004.

[35] L. J. Klesse, K. A. Meyers, C. J. Marshall, and L. J. Parada, "Nerve growth factor induces survival and differentiation through two distinct signaling cascades in PC12 cells," Oncogene, vol. 18, no. 12, pp. 2055-2068, 1999.

[36] G. Pani, N. Samari, R. Quintens et al., "Morphological and physiological changes in mature in vitro neuronal networks towards exposure to short-, middle- or long-term simulated microgravity," PLoS ONE, vol. 8, no. 9, Article ID e73857, 2013.

[37] T. B. Shea and M. L. Beermann, "Neuronal intermediate filament protein $\alpha$-internexin facilitates axonal neurite elongation in neuroblastoma cells," Cell Motility and the Cytoskeleton, vol. 43, no. 4, pp. 322-333, 1999.

[38] C.-L. Chien, T.-C. Liu, C.-L. Ho, and K.-S. Lu, “Overexpression of neuronal intermediate filament protein $\alpha$-internexin in PC12 cells," Journal of Neuroscience Research, vol. 80, no. 5, pp. 693706, 2005.

[39] V. Zimmitti, E. Benedetti, V. Caracciolo, P. Sebastiani, and S. di Loreto, "Bioreactor transient exposure activates specific neurotrophic pathway in cortical neurons," Microgravity Science and Technology, vol. 22, no. 1, pp. 37-43, 2010.

[40] S. S.-S. Wang and T. A. Good, "Effect of culture in a rotating wall bioreactor on the physiology of differentiated neuron-like PC12 and SH-SY5Y cells," Journal of Cellular Biochemistry, vol. 83, no. 4, pp. 574-584, 2001.

[41] T. B. Shea and M. L. Beermann, "Respective roles of neurofilaments, microtubules, MAP1B, and tau in neurite outgrowth and stabilization," Molecular Biology of the Cell, vol. 5, no. 8, pp. 863875, 1994.

[42] W. Lin and B. G. Szaro, "Neurofilaments help maintain normal morphologies and support elongation of neurites in Xenopus laevis cultured embryonic spinal cord neurons," The Journal of Neuroscience, vol. 15, no. 12, pp. 8331-8344, 1995. 
[43] S. Higgins, J. S. Lee, L. Ha, and J. Y. Lim, "Inducing neurite outgrowth by mechanical cell stretch," BioResearch Open Access, vol. 2, no. 3, pp. 212-216, 2013.

[44] I. A. Kim, S. A. Park, Y. J. Kim et al., "Effects of mechanical stimuli and microfiber-based substrate on neurite outgrowth and guidance," Journal of Bioscience and Bioengineering, vol. 101, no. 2, pp. 120-126, 2006.

[45] R. M. Grumbles, V. W. Almeida, G. T. B. Casella, P. M. Wood, K. Hemstapat, and C. K. Thomas, "Motoneuron replacement for reinnervation of skeletal muscle in adult rats," Journal of Neuropathology and Experimental Neurology, vol. 71, no. 10, pp. 921-930, 2012.

[46] S. Ostrovidov, S. Ahadian, J. Ramon-Azcon et al., "Threedimensional co-culture of $\mathrm{C} 2 \mathrm{C} 12 / \mathrm{PC} 12$ cells improves skeletal muscle tissue formation and function," Journal of Tissue Engineering and Regenerative Medicine, 2014.

[47] S. Karumbayaram, B. G. Novitch, M. Patterson et al., "Directed differentiation of human-induced pluripotent stem cells generates active motor neurons," Stem Cells, vol. 27, no. 4, pp. 806-811, 2009.

[48] J. J. W. A. Van Loon, F. Wuyts, N. Bäcker et al., "The large radius human centrifuge: a human hypergravity habitat," in Proceedings of the 60th International Astronautical Congress (IAC '09), vol. 1, pp. 131-134, 2009. 


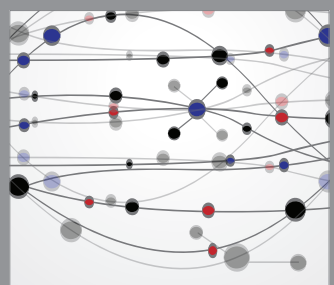

The Scientific World Journal
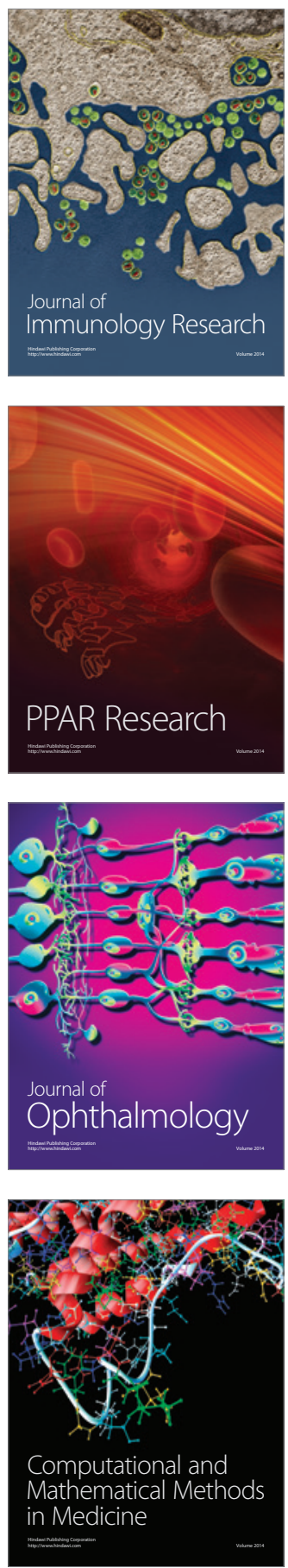

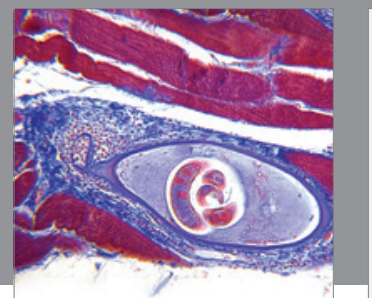

Gastroenterology

Research and Practice
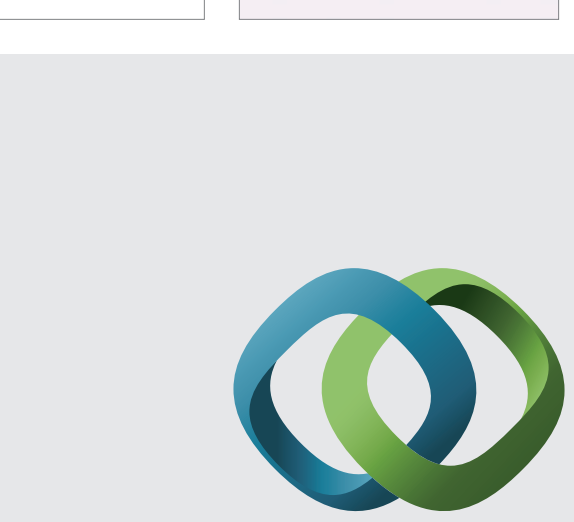

\section{Hindawi}

Submit your manuscripts at

http://www.hindawi.com
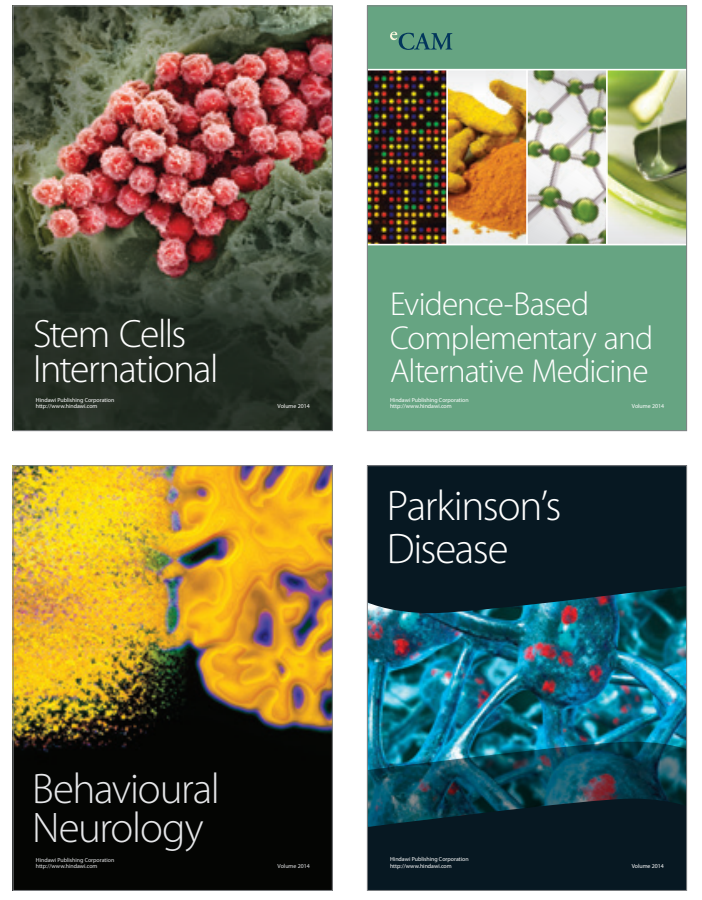
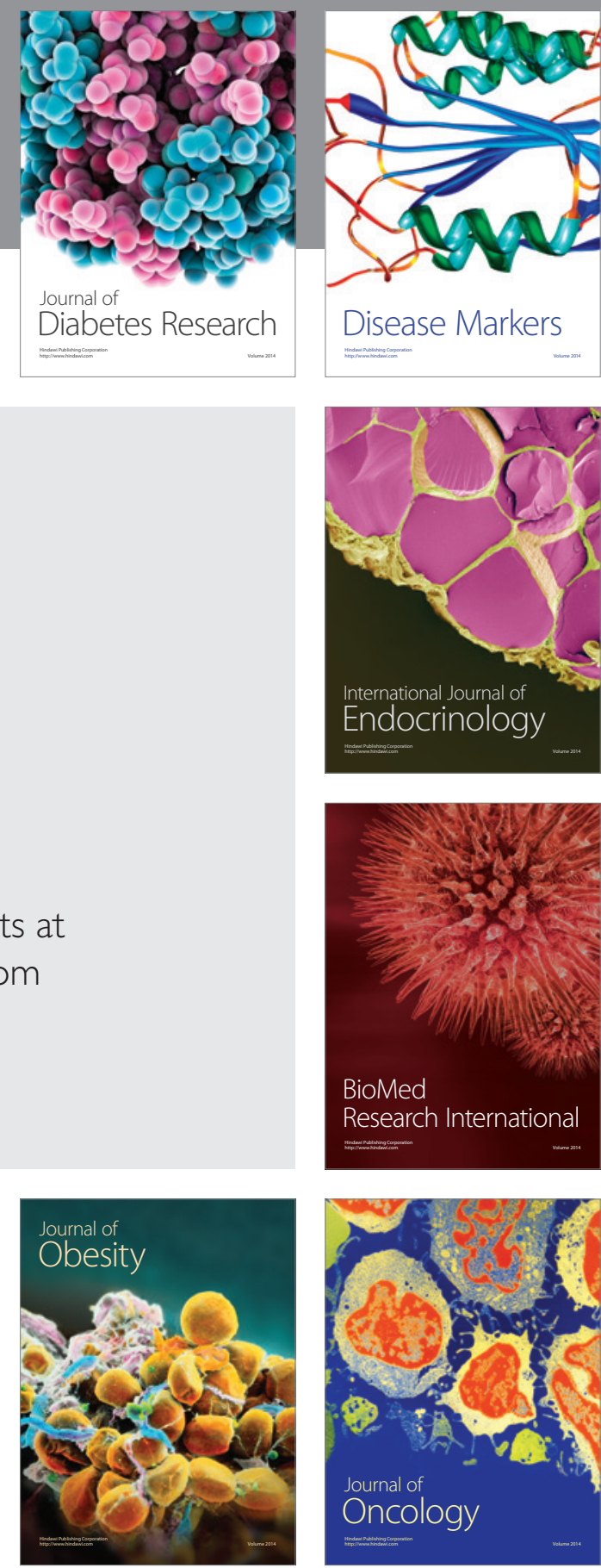

Disease Markers
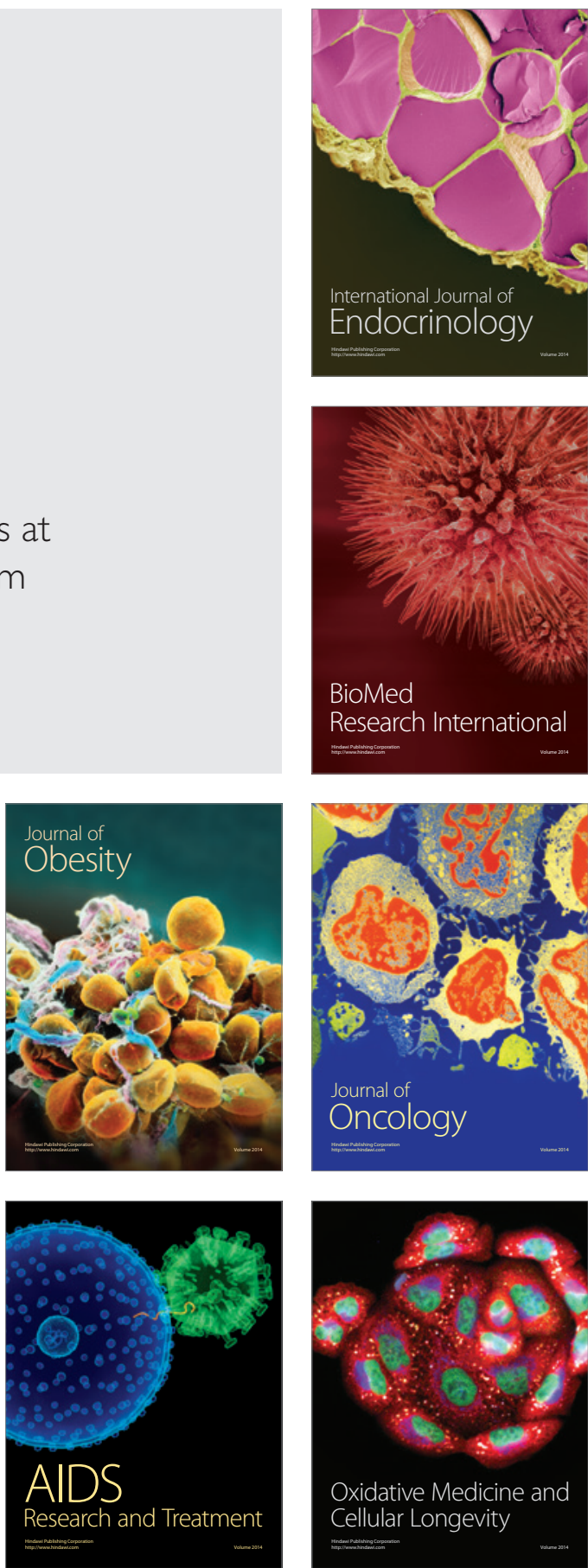